\title{
Laparoscopic Herniotomy for congenital inguinal hernia: prospective assessment of feasibility and outcome analysis in tertiary center in Nepal
}

\author{
Dr Ritesh Shrestha, Dr Sudip Shrestha \\ Department of Surgery, Nepal Medical College Teaching Hospital, Attarkhel, Jorpati, Kathmandu, Nepal \\ Correspondence: Dr Ritesh Shrestha, Department of Surgery, Nepal Medical College Teaching Hospital
}

Email: surgritesh@gmail.com

\begin{tabular}{l} 
Abstract \\
\hline \hline Introduction: Congenital Inguinal hernia (CIH) repair is frequently performed surgical procedures \\
in children. Open herniotomy is standard treatment for CIH. However, in developed countries \\
laparoscopic repair is gaining popularity. The benefits of laparoscopic hernia repair are its safety, cosmetic \\
results, opportunity to repair contralateral patent processus vaginalis (CPPV). The aim of this study was \\
to assess feasibility and outcome of Laparoscopic herniotomy (LH) in tertiary center in Nepal. \\
Methods: This is prospective observational study conducted at Nepal Medical College Teaching \\
Hospital, Pediatric Surgery Unit from 1 st November 2015 to $30^{\text {th }}$ October 2016 . All children of \\
age greater than six months with CIH were included in this study after consent from parents. \\
Demographic profile, operative findings, postoperative results, complications and recurrences were \\
recorded. \\
Results: We had 60 children, 45 males and 15 females who underwent laparoscopic herniotomy. \\
33 of them had right, 24 had left and 3 had bilateral hernias. The mean operating time was 30.12 \\
minutes and 35 minutes for unilateral and bilateral hernias respectively. 14 were associated with \\
CPPV and were repaired in same setting. We had one recurrence on right side and were repaired \\
with open herniotomy. \\
Conclusion: Laparoscopic herniotomy is feasible and safe in CIH. It provides better opportunity to \\
diagnose CPPV and repair it. LH has got minimal complication and better cosmetic outcome. Larger \\
studies and longer follow ups are needed to support our results. \\
Keywords: Congenital Hernia; Feasibility; Laparoscopic Herniotomy. \\
\hline \hline
\end{tabular}

\section{Introduction}

An inguinal hernia is one of the common surgical problems in pediatric age group. Congenital inguinal hernia results due to the persistence of processus vaginalis. ${ }^{1}$ Not all cases of PPV result in inguinal hernia. The childhood risk of developing an inguinal hernia if there is a PPV is between $25 \%$ and $50 \%$. $^{2}$

The reported incidence of $\mathrm{CIH}$ ranges from $1-5 \%$. As involution of the left processes vaginalis precedes that of right, $\mathrm{CIH}$ is common on the right side $(60 \%)$. Premature infants are at increased risk for inguinal hernia, with an incidence of $2 \%$ in females and $7-30 \%$ in males. ${ }^{3,4}$
Congenital inguinal hernia require operation, since they risk obstruction and incarceration. Under 1 year age the incarceration rate is up to $30 \%$ which drops to $15 \%$ by 18 months age. ${ }^{5}$ Strangulation is also reported to occur in between 2 to $33 \%$ of girls with inguinal hernias with an irreducible ovary. ${ }^{6}$

The definitive management of inguinal hernia is surgical repair, which involves excision of hernia sac and high ligation of processus vaginalis. ${ }^{7}$ Surgery may be done as open or laparoscopic repair.

Boys with inguinal hernia can also have intra-operative 
injury to the vas deferens, with the development of sperm agglutinating antibodies. . $^{8,9,10}$

Traditionally open herniotomy is the operation of choice for pediatric hernia repair. However now laparoscopic hernia repair is gaining popularity due to its safety and cosmetic benefits.

\section{Methods}

The study was conducted at Nepal Medical College Teaching Hospital, Department of Surgery from $1^{\text {st }}$ November 2015 to $30^{\text {th }}$ October 2016. All the children with congenital inguinal hernias were included in our study with due consent from the parents. However, exclusion criteria included were prematurity, age $<6$ months, irreducible or recurrent hernia. Operative findings, postoperative results and complications were assessed. The patients were followed up for one year duration on Out- patient basis or via telephone calls.

All the procedures were done under general anesthesia with endotracheal intubation. The hernia were reduced manually before the procedure if they still persist after intubation. One dose of intra-operative Ceftriaxone $(50 \mathrm{mg} /$ $\mathrm{kg}$ /day in 2 divided dose) was given intra venous to all patients after checking hypersensitivity reaction. A $5 \mathrm{~mm}$ telescope was inserted through the $5 \mathrm{~mm}$ umbilical port and pneumoperitoneum was created with $\mathrm{CO}_{2}$ gas to $10 \mathrm{mmHg}$. Two stab incisions were made with no.11 surgical blade in midclavicular line at the level of umbilicus and $3 \mathrm{~mm}$ working instruments were introduced. The internal inguinal orifices at the side of hernia and also the contralateral side were inspected. As we have excluded obstructed hernia, in most cases only open rings were visualized. However in some, omentum was seen to be passing through the ring, which were reduced with non-traumatic bowel grasper. A purse string suture was placed around the orifice using 3-0 Polyglactin suture. The abdomen was desufflated and umbilical port was closed with 3-0 polygalactin suture (Vicryl). The skin incisions were closed with cyanoacrylate glue. Patient was then extubated and shifted to postoperative ward. All patients were allowed oral diet three hours after extubation.

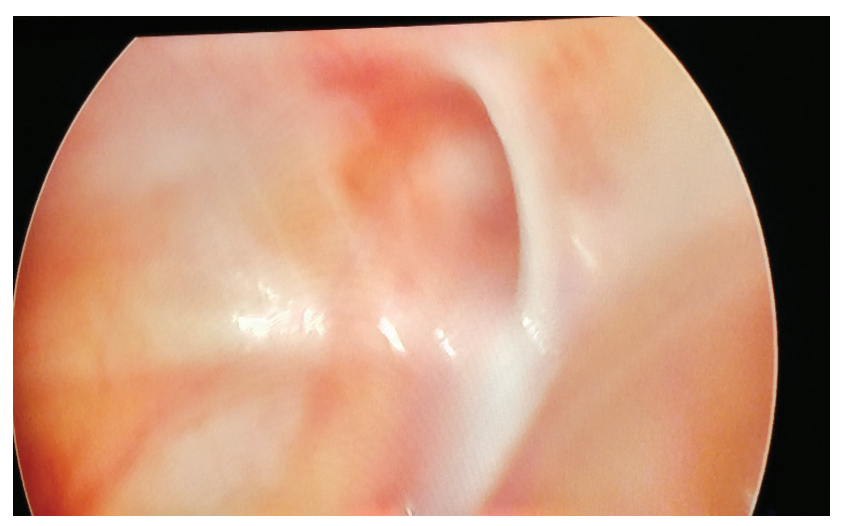

Figure 1. Patent internal ring

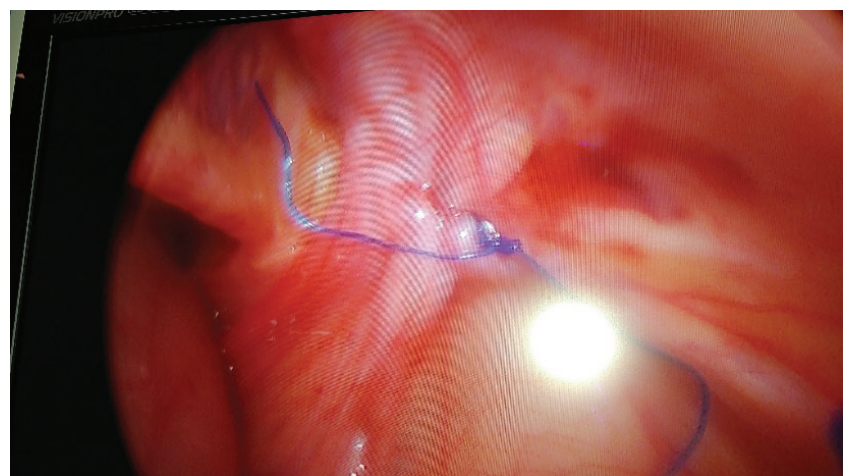

Figure 2. Laparoscopic ring closure

All the patients were observed in the post-operative ward and later in the ward. The Children and Infants Postoperative Pain Score (CHIPPS) was used to record the pain level in infants and young children $\leq 3$ years of age for $0,6,12$, and 24 hours after the surgery. For children $>3$ years of age, Children's Hospital of Eastern Ontario Pain Score (CHEOPS) was used. Patients with CHIPPS $\geq 4$ or CHEOPS $\geq 5$ were given acetaminophen $15 \mathrm{mg} /$ $\mathrm{kg}$ /dose orally and repeated every 6 hours as required, up to a maximum of $90 \mathrm{mg} / \mathrm{kg} /$ day. Patients were then called for immediate follow up after seven days and a month to inspect the wound.

Descriptive analysis of the recorded data was done using SPSS 18.

\section{Results}

Sixty children underwent laparoscopic herniotomy in 1 year study period. (Table 1) There were 45 males and 15 females. Ages of children ranged from 1 year to 14 years with mean of 5.8 years. Right inguinal hernia was found in 33 children, left in 24 children and bilateral in 3 children. The operative time ranged from 15 to 50 minutes and mean operative time was 30.13 minutes for unilateral hernia and 35 minutes for bilateral hernia. (Table 1)

There were 14 associated Contralateral Patent Processus Vaginalis (CPPV) and they were repaired in same settings. (Table 2) There was no conversion to open surgery. In postoperative period visual analog pain scores were calculated at $0,6,12$ and 24 hours after surgery. The average pain scores were $3.28,4,3.4$ and 2.18 after 0,6 , 12 and 24 hours respectively (Table 3 ). All the patients were discharged on the first postoperative day with oral analgesics. There was a single recurrence in a right sided hernia (Table 2) after 3 months of surgery and open herniotomy was done for it. We did not have any cases of surgical site infection, bleeding, urinary retention or immediate recurrence before discharge. 
Table 1: Demographic data

\begin{tabular}{|c|c|}
\hline Parameters & Observations \\
\hline Total no. of cases & 60 \\
\hline Sex & $\begin{array}{l}\text { Male }=45(75 \%), \text { Female }=15 \\
(25 \%)\end{array}$ \\
\hline Mean Age & 5.8 years $(\mathrm{SD}=3.67)$ \\
\hline Side of hernia & $\begin{array}{l}\text { Right }=33(55 \%), \text { Left }=24(40 \%), \\
\text { Bilateral }=3(5 \%)\end{array}$ \\
\hline
\end{tabular}

Table 2: Operative and post-operative data

\begin{tabular}{ll} 
Parameters & Observations \\
Mean operative Duration & \\
\multicolumn{1}{c}{ Unilateral hernia } & 30.13 minutes (15-50 min) \\
Bilateral hernia & 35 minutes (30-40 min) \\
CPPV & 14 cases \\
Recurrence & 1 \\
Conversion & Nil
\end{tabular}

Table 3: Pain Score

\begin{tabular}{|c|c|c|}
\hline Pain Score at & Mean Score (Range) & SD \\
\hline 0 hours & $3.28(1-5)$ & 0.94 \\
\hline 6 hours & $4(2-7)$ & 0.89 \\
\hline 12 hours & $3.4(2-6)$ & 0.96 \\
\hline 24 hours & $2.18(1-4)$ & 0.79 \\
\hline
\end{tabular}

\section{Discussion}

Inguinal hernia is the common problem in pediatric age group. Most children present during their first year of life. Regardless of age of presentation, all hernias in children are likely to be due to failure of the processus vaginalis to close completely during fetal and newborn development. Inguinal hernia will not close spontaneously, and because of the high risk of incarceration, surgical closure is always indicated. Most surgeons recommend repair soon after diagnosis.

The fundamental principle guiding pediatric inguinal hernia repair is high ligation of the hernia sac. Open herniotomy has been the gold standard operation of choice as it is credited with being easy to perform, having high success rate and fewer complications.

In 1975, the first laparoscopic surgery was done in pediatric patient to treat intestinal obstruction and it laid milestone in development of pediatric laparoscopic surgery. ${ }^{11}$ In 1997, the first laparoscopic repair of inguinal hernia in pediatric patient was described by El-Gohary. ${ }^{12}$ Initially this operation was done in girls only because there is risk of damaging vas deference and vessels in boys. Monteput and Esposito were first to use laparoscopy in the repair of inguinal hernia in male pediatric patient using intracorporeal purse string suture to close the ring. ${ }^{13}$ In 2003, Chan and Tam added intracorporeal hydro dissector to avoid vas and vessel damage. ${ }^{14}$ In the same year Prasad and colleagues used extracorporeal suturing to repair hernia. ${ }^{15}$ Since then much progress has been done in pediatric laparoscopic surgery which leads us to do laparoscopic repair of congenital inguinal hernia safely.

Nowadays with much advances in minimally invasive surgery, congenital inguinal hernia has been routinely treated by the laparoscopic method. Since its advent, there has been considerable evolution with the introduction of number of innovations, each maintaining basic principle of surgical repair of pediatric inguinal hernia -high ligation of sac. Laparoscopic repair has many advantages like less pain, earlier return to daily activities, repair of bilateral hernia through same ports, less chance of injury to vas, good cosmetic outcome and easier to repair recurrent hernia. Laparoscopy in pediatric hernia also has big advantage of detecting CPPV and repair it in same setting, however there is prolonged learning curve for the surgeons.

Laparoscopic herniotomy has been discredited for longer operating time in comparison to open herniotomy. However, 2015 published a systematic review of 5 randomized trials was published, with total 553 children comparing open and laparoscopic herniotomy favoring laparoscopic herniotomy for no significant difference in operative time for unilateral hernia. ${ }^{16}$ In another systematic review by Esposito in 2014, the authors published that laparoscopic herniotomy was faster than open herniotomy for bilateral hernias $(p=0.01)$ and there was no significant difference for unilateral hernia repair $(p=0.33) .{ }^{17}$ Similarly in another meta-analysis by Yang in 2010 stated shorter operative time for bilateral hernia $(\mathrm{p}=0.02)$ for laparoscopic repair and no significant difference for unilateral hernia in both groups. ${ }^{18}$ However in our context the mean operating time is 30.13 minutes for unilateral and 35 minutes for bilateral hernias. The increased average time in our study as compared to the 
other centers may be due to our early experience to the laparoscopic approach.

Laparoscopic surgery has been acknowledged for shorter duration of hospital stay and early return to work. Small incision site, less post-operative pain and early mobilization have made laparoscopic surgery popular among both the patients and the surgeons. In our study, we were able to discharge all our patient in first postoperative day with full activity and controlled pain.

Less post-operative pain is an advantage of laparoscopic surgery. In our study, we accessed pain score $0,6,12$ and 24 hours after surgery. The average pain scores were 3.28 , $4,3.4$ and 2.18 after $0,6,12$ and 24 hours respectively. We have prescribed just oral acetaminophen to the patients and none required injectable analgesics. However the difference in post-operative pain between open and laparoscopic groups has not been seen significant enough to rate either surgery superior. ${ }^{19}$

In Laparoscopic hernia repair, recurrence rate of $0 \%$ $5.5 \%$ have been reported..$^{17}$ In our study, there was one recurrence $(1.6 \%), 3$ month after surgery and we did open herniotomy in that patient. There was no surgical site infection. As laparoscopic surgery significantly reduces surgical site infection that might be the key reason but also the intra-operative antibiotic might have helped to reduce the incidence..$^{20}$ Also we did not have any bleeding or postoperative urinary retention probably because unlike in adult laparoscopic hernia repair, pediatric patients did not require narcotic analgesics and also no need to do any dissection or placement of mesh.

Our study demonstrates that it is possible to do laparoscopic hernia repair in pediatric inguinal hernia with minimal complication. Though there have been reports of laparoscopic hernia repair in adults from our country the reports in pediatric patients are not available. ${ }^{22,23}$ However we do have reports from neighboring country mentioning laparoscopic hernia repair in pediatric patients are simple and safe procedure.$^{24,25}$

\section{Conclusion}

Laparoscopic herniotomy is feasible and safe for pediatric hernia repair even in developing countries. It provides a superior tool to diagnose CPPV that can be managed in same session and also offers better surgical and cosmetic outcome. Larger studies and longer follow-up are needed to support our encouraging results.

\section{Acknowledgement}

We would like to thank Dr Krishna Prasad Devkota, consultant pediatric surgeon and pediatric surgery unit head at Nepal Medical College for his support and guidance.

\section{References}

1. Coran AG, Adzick NS, Krummel TM, Laberge JM, Shamberger AC, Robert C.Pediatric Surgery.7th ed. Elsevier Saunder;2012. 985-1001

2. Grosfeld JL. Current concepts in inguinal hernia in infants and children. World J Surg 1989;13(5):506-16; https://doi.org/10.1007/BF01658863; PMid:2573200

3. Peevy KJ, Speed FA, Hoff CJ. Epidemiology of Hernia in preterm neonates. Pediatric 1986; 77: 246-7

4. Pan ML, Chang WP, Lee HC. A longitudinal cohort study of incidence rates of inguinal hernia repair in 0 to 16 year old children. J Pediatr Surg 2013;48:2327-31 https://doi.org/10.1016/j.jpedsurg.2013.06.004; PMid:24210207

5. Grosfeld JL. Hernias in children. Rob and SmithOs Operative Surgery: Pediatric surgery EDs. Spitz L, Coran AG. Chapman and Hall, London 1995;222-38.

6. Boley SJ, Cahn D, Lauer T. The irreducible ovary: a true emergency. J Pediatr Surg 1991;26:1035-8; https://doi.org/10.1016/0022-3468(91)90668-J.

7. Spurbeck WW, Prasad R,Lobe TE. Two-year experience with minimally invasive herniorrhaphy in children. Surg Endosc 2005;19:551-3; https://doi. org/10.1007/s00464-004-8922-x; PMid:15696361.

8. Puri P, Guiney EJ, O'Donnell B. Inguinal hernia in infants: the fate of the testis following incarceration. J Pediatr Surg 1984;19:44-6; https://doi.org/10.1016/ S0022-3468(84)80013-5.

9. Walc L, Bass J, Rubin S, Walton M. Testicular fate after incarcerated hernia repair and / or orchiopexy performed in patients under 6 months of age. J Pediatr Surg 1995;30:1195-7 https://doi.org/10.1016/0022-3468(95)90020-9.

10. Matsuda T, Muguruma K,Horii Y. Serum antisperm antibodies in men with vas deferens obstruction caused by childhood inguinal herniorrhaphy. Fertil Steril 1993;59:1095-7 https://doi.org/10.1016/S0015-0282(16)55934-2. 
11. Becmeur F Videosurgery-the second generation. J Pediatr Surg 2011; 46:275-279 https://doi.org/10.1016/j.jpedsurg.2010.11.001; PMid:21292072.

12. El Gohary MA. Laparoscopic ligation of inguinal hernia in girls. Pediatr Endosurgery Innov Techn 1997;1:18588; https://doi.org/10.1089/pei.1997.1.185.

13. Montupet P, Esposito C. Laparoscopic treatment of congenital inguinal hernia in children.J Pediatr Surg 1999;34:420-3; https://doi.org/10.1016/S00223468(99)90490-6.

14. Chan KL, Tam PKH. A safe laparoscopic technique for the repair of inguinal hernia in boys. J Am Coll Surg 2003;196;987-89; $\quad$ https://doi.org/10.1016/S10727515(03)00121-2.

15. Prasad R, Lovvorn HN, Wadie GM, Lobe TE. Early experience with needlescopic Inguinal herniorrhaphy in children. J Pediatr Surg 2003;38:1055-58. https://doi.org/10.1016/S0022-3468(03)00191-X.

16. Feng S, Zhao L, Liao Z, Chen X. Open Versus Laparoscopic Inguinal Herniotomy in Children: A Systematic Review and Meta-Analysis Focusing on. Surg Laparosc Endosc Percutan Tech. 2015;25(4):27580. https://doi.org/10.1097/SLE.0000000000000161; PMid:26018053.

17. Esposito C, St. Peter SD, Escolino M, Juang D, Settimi A, Holcomb GW. Laparoscopic Versus Open Inguinal Hernia Repair in Pediatric Patients: A Systematic Review. J Laparoendosc Adv Surg Tech. 2014;24(11):811-8. https://doi.org/10.1089/ lap.2014.0194; PMid:25299121.

18. Esposito C, St. Peter SD, Escolino M, Juang D, Settimi A, Holcomb GW. Laparoscopic Versus Open Inguinal Hernia Repair in Pediatric Patients: A Systematic Review. J Laparoendosc Adv Surg Tech. 2014;24(11):811-8. https://doi.org/10.1089/ lap.2014.0194; PMid:25299121.

19. Bharathi RS, Arora M, Baskaran V. Pediatric inguinal hernia: laparoscopic versus open surgery. J Soc Laparoendosc Surg. 2008;12(3):277-81.
20. Varela JE et al. Laparoscopic surgery significantly reduces surgical site infections compared with open surgery. Surg Endosc.2010. https://doi.org/10.1007/ s00464-009-0569-1.

21. Patel JA, Kaufman AS, Howard RS, Rodriguez CJ, Jessie EM. Risk factors for urinary retention after laparoscopic inguinal hernia repairs. SurgEndosc.2015;29(11):3140-5. https://doi.org/10.1007/s00464-014-4039-z.

22. Bhatterai SM,Simkhada G, Shah T, Gupta RK. Laparoscopic inguinal hernia (total extra-peritoneal): tips and tricks. Journal of society of surgeons of Nepal. 2015;18(3).

23. Shakya VC, Sood S, Bhatterai BK, Agrawal CS, Adhikari S. Laparoscopic inguinal hernia repair: a prospective evaluation of Easrtern Nepal. The PAN African Medical Journal. 2014;17:241. Doi: 10.11604/ pamj.2014.17.241.2610. https://doi.org/10.11604/ pamj.2014.17.241.2610.

24. P Chinnaswamy, Malladi V, Jani KV, Parthasarthi R, Shetty RA, Kavaokat AJ, Prakash A. Laparoscopic Inguinal Hernia in Children. Journal of the society of Laparoendoscopic Surgeons. 2005;9(4):393-9

25. Shalaby RY, Fawy M, Soliman SM, Dorgham A. Needlescopicherniorrhaphy in children-a simplified technique. J Indian Assoc Pediatr Surg. 2005;10:168-71. https://doi.org/10.4103/0971-9261.16969. 